\title{
Lattice Enthalpies of Lanthanide Orthovanadates $\mathrm{LnVO}_{4}$
}

Dimitar Petrov

\author{
Department of Physical Chemistry, Plovdiv University, 24, Tsar Asen Str., 4000 Plovdiv, Bulgaria
}

RECEIVED JUNE 10, 2013; REVISED JANUARY 15, 2014; ACCEPTED JANUARY 27, 2014

\begin{abstract}
Lattice enthalpies $\Delta_{\mathrm{L}} H^{\circ}$ of lanthanide orthovanadates, $\mathrm{LnVO}_{4}(\mathrm{Ln}=\mathrm{Ce}-\mathrm{Lu}$, except Pm $)$ have been determined from the Born-Haber thermochemical cycle and compared with those calculated by an empirical equation. Two different sets of enthalpies of formation of $\mathrm{LnVO}_{4}$, from oxides $\left(\operatorname{Ln}_{2} \mathrm{O}_{3}, \mathrm{~V}_{2} \mathrm{O}_{5}\right)$ and from elements, have been used but the differences in $\Delta_{\mathrm{L}} H^{\circ}$ are small. The Born-Haber cycle in both routes yields close values of $\Delta_{\mathrm{L}} H^{\circ}$ to those obtained after an empirical equation proposed by Glasser and Jenkins. It has been found that the partial derivative of the lattice enthalpies to the molar volumes corresponds by magnitude and dimension to the shear moduli of these crystals. (doi: 10.5562/cca2298)
\end{abstract}

Keywords: lattice enthalpies, lanthanide orthovanadates, shear moduli, thermochemistry, Born-Haber cycle

\section{INTRODUCTION}

Lanthanide orthovanadates, $\mathrm{LnVO}_{4}(\mathrm{Ln}=\mathrm{Ce}-\mathrm{Lu})$ exhibit valuable catalytic, electric, magnetic and optical properties. Recent experimental studies comprise, e.g. photoconversion of cyclohexane and benzene by $\mathrm{LnVO}_{4}$ $(\mathrm{Ln}=\mathrm{Ce}, \mathrm{Pr}, \mathrm{Nd}){ }^{1}$ visible-light photocatalysis by $\mathrm{NdVO}_{4}$ nanowires, ${ }^{2}$ laser applications and optoelectronic characteristics, ${ }^{3-5}$ electronic, mechanical and optical properties of $\mathrm{GdVO}_{4}{ }^{6}$, charge-transfer transitions in $\mathrm{LnVO}_{4}(\mathrm{Ln}=\mathrm{Gd}, \mathrm{Lu}): \mathrm{Eu}^{3+}$, electronic structure of $\mathrm{CeVO}_{4}$ from diffuse reflectance spectroscopy. ${ }^{8}$ Theoretical studies deal with magnetic properties of $\mathrm{LnVO}_{4}$ $(\mathrm{Ln}=\mathrm{Eu}, \mathrm{Ho}, \mathrm{Lu}),{ }^{9}$ phase analyses of $\mathrm{DyVO}_{4},{ }^{10}$ band structure calculations of $\mathrm{CeVO}_{4},{ }^{8}$ local spin densities and band structure of $\mathrm{GdVO}_{4}{ }^{6} \mathrm{LnVO}_{4}$ crystallize in zircon-type $\left(\mathrm{ZrSiO}_{4}\right)$ structure with $\mathrm{I}_{1} /$ amd space group (No. 141) and four molecules per unit cell $;{ }^{11}$ they melt at high temperature, $T_{\mathrm{m}}=1710-2100 \mathrm{~K}^{12}$

The thermodynamic assessment of lanthanide orthovanadates is incomplete, although, e.g. five different sets exist in the changes of the standard enthalpy (CSE) of formation with values varying about $50 \mathrm{~kJ} \mathrm{~mol}^{-1}$ for $\mathrm{SmVO}_{4}{ }^{13,14}$ In Ref. 13, CSE of formation of $\mathrm{LnVO}_{4}(\mathrm{Ln}=\mathrm{Ce}-\mathrm{Lu}$, except $\mathrm{Pm}, \mathrm{Yb})$ from oxides and from elements have been determined at $T=298.15 \mathrm{~K}$ and at $T=1075 \mathrm{~K}$ in solvent of lead borate $\left(2 \mathrm{PbO} \times 2 \mathrm{~B}_{2} \mathrm{O}_{3}\right)$. Bond energies of $\mathrm{LnVO}_{4}(\mathrm{Ln}=\mathrm{Ce}-$ $\mathrm{Lu}$, except $\mathrm{Pm}$ ) have been calculated using the dielectric chemical bond theory. ${ }^{15}$ In the same work, the whole crystal of $\mathrm{LnVO}_{4}$ is fragmented into a sum of binary crystals and only the energies of the bond types $\mathrm{Ln}-\mathrm{O}$, $\mathrm{Ln}-\mathrm{O}^{I}$, and $\mathrm{V}-\mathrm{O}$ have been presented. The single prime $\left.{ }^{(}\right)$indicates different bond length with the cluster $\mathrm{LnO}_{8}{ }^{I}$ compared to $\mathrm{LnO}_{8}$.

The amount of energy per mole that binds the ions in the crystal lattice of $\mathrm{LnVO}_{4}$ is among the basic characteristics of these compounds. The aim of the present work is to determine the lattice enthalpies of $\mathrm{LnVO}_{4}$ by the Born-Haber thermochemical cycle and to relate these quantities to certain mechanical properties.

\section{METHOD}

The lanthanide orthovanadates $\mathrm{LnVO}_{4}$ have a defined stoichiometry and the lattice is assumed to contain ions with integral charges. Therefore, the lattice enthalpies $\Delta_{\mathrm{L}} H^{\circ}$ can be found by the Born-Haber cycle in Eq. (1) below. The term $\mathrm{B}$ corresponds to two different CSE of formation of $\mathrm{LnVO}_{4}$ included in the cycle - from oxides or from elements (Eq. (2)):

$$
\begin{aligned}
B+ & \Delta_{\mathrm{s}} H^{\circ}(\mathrm{Ln})+\Delta_{\mathrm{s}} H^{\circ}(\mathrm{V})+2 \Delta_{\mathrm{d}} H^{\circ}(\mathrm{O}-\mathrm{O})+\Delta_{\mathrm{i}} H^{\circ}(\mathrm{Ln})+ \\
& +\Delta_{\mathrm{i}} H^{\circ}(\mathrm{V})+4 \Delta_{\mathrm{eg}} H^{\circ}(\mathrm{O})-\Delta_{\mathrm{L}} H^{\circ}\left(\operatorname{LnVO}_{4}\right)=0 \\
B= & {\left[\Delta_{\mathrm{f}, \mathrm{ox}} H^{\circ}\left(\mathrm{LnVO}_{4}\right)-\frac{1}{2} \Delta_{\mathrm{f}} H^{\circ}\left(\operatorname{Ln}_{2} \mathrm{O}_{3}\right)-\frac{1}{2} \Delta_{\mathrm{f}} H^{\circ}\left(\mathrm{V}_{2} \mathrm{O}_{5}\right)\right] } \\
& \text { or } B=\left[-\Delta_{\mathrm{f}, \mathrm{el}} H^{\circ}\left(\operatorname{LnVO}_{4}\right)\right],
\end{aligned}
$$

\footnotetext{
* Author to whom correspondence should be addressed. (E-mail: petrov_d_n@abv.bg)
} 
Table 1. Born-Haber cycle for lanthanide orthovanadates, $\mathrm{LnVO}_{4}$

\begin{tabular}{ccc}
\hline No & Equation of the process in each step & \multicolumn{1}{c}{$\Delta H^{\circ}$} \\
\hline $1 \mathrm{a}$. & $\mathrm{LnVO}_{4}(\mathrm{~s}) \rightarrow(1 / 2) \mathrm{Ln}_{2} \mathrm{O}_{3}(\mathrm{~s})+(1 / 2) \mathrm{V}_{2} \mathrm{O}_{5}(\mathrm{~s})$ & $-\Delta_{\mathrm{f}, \mathrm{ox}} H^{\circ}$ \\
$1 \mathrm{~b}$. & $(1 / 2) \mathrm{Ln}_{2} \mathrm{O}_{3}(\mathrm{~s})+(1 / 2) \mathrm{V}_{2} \mathrm{O}_{5}(\mathrm{~s}) \rightarrow \mathrm{Ln}(\mathrm{s})+\mathrm{V}(\mathrm{s})+2 \mathrm{O}_{2}(\mathrm{~g})$ & $-(1 / 2) \Delta_{\mathrm{f}} H^{\circ}\left(\left(\mathrm{Ln}_{2} \mathrm{O}_{3}\right),\left(\mathrm{V}_{2} \mathrm{O}_{5}\right)\right)$ \\
1. & $\mathrm{LnVO}_{4}(\mathrm{~s}) \rightarrow \mathrm{Ln}(\mathrm{s})+\mathrm{V}(\mathrm{s})+2 \mathrm{O}_{2}(\mathrm{~g})$ & $-\Delta_{\mathrm{f}, \mathrm{el}} H^{\circ}$ \\
2. & $\mathrm{Ln}(\mathrm{s})+\mathrm{V}(\mathrm{s})+2 \mathrm{O}_{2}(\mathrm{~g}) \rightarrow \mathrm{Ln}(\mathrm{g})+\mathrm{V}(\mathrm{s})+2 \mathrm{O}_{2}(\mathrm{~g})$ & $\Delta_{\mathrm{s}} H^{\circ}(\mathrm{Ln})$ \\
3. & $\mathrm{Ln}(\mathrm{g})+\mathrm{V}(\mathrm{s})+2 \mathrm{O}_{2}(\mathrm{~g}) \rightarrow \mathrm{Ln}(\mathrm{g})+\mathrm{V}(\mathrm{g})+2 \mathrm{O}_{2}(\mathrm{~g})$ & $\Delta_{\mathrm{s}} H^{\circ}(\mathrm{V})$ \\
4. & $\mathrm{Ln}(\mathrm{g})+\mathrm{V}(\mathrm{g})+2 \mathrm{O}_{2}(\mathrm{~g}) \rightarrow \mathrm{Ln}(\mathrm{g})+\mathrm{V}(\mathrm{g})+4 \mathrm{O}(\mathrm{g})$ & $2 \Delta_{\mathrm{d}} H^{\circ}\left(\mathrm{O}_{2}\right)$ \\
5. & $\mathrm{Ln}(\mathrm{g})+\mathrm{V}(\mathrm{g})+4 \mathrm{O}(\mathrm{g}) \rightarrow \mathrm{Ln}^{3+}(\mathrm{g})+3 \mathrm{e}^{-}+\mathrm{V}(\mathrm{g})+4 \mathrm{O}(\mathrm{g})$ & $\Delta_{\mathrm{i}} H^{\circ}(\mathrm{Ln})$ \\
6. & $\mathrm{Ln}^{3+}(\mathrm{g})+3 \mathrm{e}^{-}+\mathrm{V}(\mathrm{g})+4 \mathrm{O}(\mathrm{g}) \rightarrow \mathrm{Ln}^{3+}(\mathrm{g})+3 \mathrm{e}^{-}+\mathrm{V}^{5+}(\mathrm{g})+5 \mathrm{e}^{-}+4 \mathrm{O}(\mathrm{g})$ & $\Delta_{\mathrm{i}} H^{\circ}(\mathrm{V})$ \\
7. & $\mathrm{Ln}^{3+}(\mathrm{g})+\mathrm{V}^{5+}(\mathrm{g})+4 \mathrm{O}(\mathrm{g})+8 \mathrm{e}^{-} \rightarrow \mathrm{Ln}^{3+}(\mathrm{g})+\mathrm{V}^{5+}(\mathrm{g})+4 \mathrm{O}^{2-}(\mathrm{g})$ & $4 \Delta_{\mathrm{eg}} H^{\circ}(\mathrm{O})$ \\
8. & $\mathrm{Ln}^{3+}(\mathrm{g})+\mathrm{V}^{5+}(\mathrm{g})+4 \mathrm{O}^{2-}(\mathrm{g}) \rightarrow \mathrm{LnVO}_{4}(\mathrm{~s})$ & $-\Delta_{\mathrm{L}} H^{\circ}$ \\
\hline
\end{tabular}

where the notation is as follows: ${ }^{16}$ the left-hand side subscript to each enthalpy refers to, respectively: $\mathrm{L}$ - lattice, $\mathrm{f}$ - formation, $\mathrm{f}$, ox - formation from oxides, $\mathrm{f}$, el - formation from elements, s-sublimation, i - ionization, $\mathrm{d}$ - dissociation, and eg - electron gain; the righthand side superscript $\left({ }^{\circ}\right)$ indicates "under standard conditions": temperature $T=298.15 \mathrm{~K}$, pressure $p=$ $101325 \mathrm{~Pa}$. The CSE are related to the corresponding energies of dissociation, electron gain, ionization, sublimation, and potential energy of the lattice according to the formulae, respectively:

$$
\begin{aligned}
& \Delta_{\mathrm{d}} H^{\circ}=-\Delta_{\mathrm{d}} U^{\circ}-\frac{5}{2} R T, \\
& \Delta_{\mathrm{eg}} H^{\circ}=-\left(\Delta_{\mathrm{eg}} U^{\circ}-5 R T\right), \\
& \Delta_{\mathrm{i}} H^{\circ}=\Delta_{\mathrm{i}} U^{\circ}+n \frac{5}{2} R T, n=3 \text { for Ln, or } n=5 \text { for V, } \\
& \Delta_{\mathrm{s}} H^{\circ}=\Delta_{\mathrm{s}} U^{\circ}+\frac{5}{2} R T ; \\
& \operatorname{LnVO}_{4}(\mathrm{~s}) \rightarrow \mathrm{Ln}^{3+}(\mathrm{g})+4 \mathrm{O}^{2-}(\mathrm{g}), \\
& \Delta n(\mathrm{~g})=+6 \mathrm{~mol} ; \Delta_{\mathrm{L}} H^{\circ}=-\Delta_{\mathrm{L}} U^{\circ}-3 R T .
\end{aligned}
$$

The input data for the calculation of $\Delta_{\mathrm{L}} H^{\circ}$ are presented in Table 2 and Table 3. The equation of each step (physical or chemical change) of the cycle is given in

Table 2. Standard enthalpy changes of vanadium and oxygen

\begin{tabular}{cc}
\hline$\Delta H^{\circ} / \mathrm{kJ} \mathrm{mol}^{-1}$ & Value \\
\hline$\Delta_{\mathrm{i}} H^{\circ}(\mathrm{V})$ & $15729.9 \pm 1.2^{(\mathrm{a})}$ \\
$\Delta_{\mathrm{f}} H^{\circ}\left(\mathrm{V}_{2} \mathrm{O}_{5}\right)$ & $-1550.6^{(\mathrm{a})}$ \\
$\Delta_{\mathrm{s}} H^{\circ}(\mathrm{V})$ & $515.8 \pm 0.1^{(\mathrm{b})}$ \\
$\Delta_{\mathrm{d}} H^{\circ}\left(\mathrm{O}_{2}\right)$ & $498.36 \pm 0.17^{(\mathrm{a})}$ \\
$\Delta_{\mathrm{eg}} H^{\circ}(\mathrm{O})$ & $715.4^{\text {(c) }}$ \\
\hline
\end{tabular}

Data taken from: ${ }^{(a)}$ Ref. 17; ${ }^{(b)}$ Ref. 18; ${ }^{(c)}$ Ref. 16.
Table 1. The sign of the CSE must be reversed if the actual processes take place in the opposite direction. The overall sum of CSE is equal to zero for a closed path of changes starting and ending at the same state. Here, the final step is the formation of lanthanide orhovanadate in solid phase, $\mathrm{LnVO}_{4}(\mathrm{~s})$, from a gas of separated ions. This process is reverse to that one in the definition of lattice energy as displayed in the last row of Eq. (3).

\section{RESULTS AND DISCUSSION}

The lattice enthalpies obtained in this work are presented in Table 4. The values of the CSE of $\mathrm{LnVO}_{4}$ lattice determined by the Born-Haber thermochemical cycle vary in a narrow range, about $1.1-1.4 \%$ within the lanthanide series to the mean value, respectively for those determined from CSE of formation of $\mathrm{LnVO}_{4}$ from oxides or from elements.

The Born-Haber cycle presented in Table 1 may start with either steps $1 \mathrm{a}$ and $1 \mathrm{~b}$ (reverse process of the formation of $\mathrm{LnVO}_{4}$ from oxides) or with step 1 (reverse process of the formation of $\mathrm{LnVO}_{4}$ from elements) and then to proceed further via step 2, etc. The values of $-\Delta_{\mathrm{f}, \mathrm{el}} H^{\mathrm{o}}$ have been used in this study since they comprise all $\mathrm{LnVO}_{4}$ except $\mathrm{PmVO}_{4}$.

The range of $\Delta_{\mathrm{L}} H^{\circ}$ variation is small as the formation of $\mathrm{LnVO}_{4}$ is determined mainly by the change of $\mathrm{Ln}^{3+}$ ionic radii appropriate to the zircon structure and by the ionic $\mathrm{Ln}-\mathrm{O}$ bonds. ${ }^{9}$ The accuracy of each lattice enthalpy $\Delta_{\mathrm{L}} H^{\circ}$ has been evaluated with the aid of the available accuracies of the quantities included in Eq. (1). Since the uncertainties for some quantities in Table 2 are not available, the RMS deviations of $\Delta_{\mathrm{L}} H^{\circ}$ determined in this work should not be lower than $0.1 \%$.

$\Delta_{\mathrm{L}} H^{\circ}$ in this work are compared in Table 4 with an empirical equation for lattice potential energy $\Delta_{\mathrm{L}} U$ (or $\left.U_{\text {РОт }}\right) .{ }^{19}$ The equation has the following form: 
Table 3. Standard enthalpy changes of formation of lanthanide orthovanadates and sesquioxides, and of sublimation and ionization of lanthanide metals (all in $\mathrm{kJ} \mathrm{mol}^{-1}$ )

\begin{tabular}{cccccc}
\hline $\mathrm{LnVO}_{4}$ & $-\Delta_{\mathrm{f}, \mathrm{el}} H^{\mathrm{o}(\mathrm{a})}$ & $-\Delta_{\mathrm{f}, \mathrm{ox}} H^{\mathrm{o}(\mathrm{b})}$ & $-\Delta_{\mathrm{f}} H^{\circ}\left(\operatorname{Ln}_{2} \mathrm{O}_{3}\right)^{(\mathrm{c})}$ & $\Delta_{\mathrm{s}} H^{\circ}(\mathrm{Ln})^{(\mathrm{c})}$ & $\Delta_{\mathrm{i}} H^{\circ}(\mathrm{Ln})^{(\mathrm{d})}$ \\
\hline $\mathrm{CeVO}_{4}$ & 1820.4 & $202.4 \pm 5.2$ & 1796.2 & 422.6 & $3541.7 \pm 9.9$ \\
$\mathrm{PrVO}_{4}$ & 1821.0 & $123.3 \pm 1.4$ & 1809.6 & 355.6 & $3646.1 \pm 9.9$ \\
$\mathrm{NdVO}_{4}$ & 1815.2 & $127.5 \pm 2.0$ & 1807.9 & 327.6 & $3715.8 \pm 38.6$ \\
$\mathrm{SmVO}_{4}$ & 1814.5 & $114.9 \pm 1.9$ & $1823.0 \pm 3.0$ & 206.7 & $3887.7 \pm 38.6$ \\
$\mathrm{EuVO}_{4}$ & 1729.3 & $105.4 \pm 1.9$ & $1651.4 \pm 12.1$ & 175.3 & $4054.3 \pm 10.9$ \\
$\mathrm{GdVO}_{4}$ & 1810.6 & $105.4 \pm 1.9$ & $1819.6 \pm 12.1$ & 397.5 & $3768.1 \pm 19.3$ \\
$\mathrm{TbVO}_{4}$ & 1826.0 & $104.2 \pm 1.8$ & $1865.2 \pm 7.5$ & 388.7 & $3808.7 \pm 19.3$ \\
$\mathrm{DyVO}_{4}$ & 1818.2 & $74.0 \pm 1.7$ & $1863.1 \pm 7.5$ & 290.4 & $3916.3 \pm 37.4$ \\
$\mathrm{HoVO}_{4}$ & 1823.3 & $108.8 \pm 1.5$ & $1880.7 \pm 4.8$ & 300.8 & $3941.5 \pm 19.3$ \\
$\mathrm{ErVO}_{4}$ & 1827.8 & $73.2 \pm 2.9$ & $1897.9 \pm 1.9$ & 317.1 & $3952.4 \pm 19.3$ \\
$\mathrm{TmVO}_{4}$ & 1819.2 & $91.1 \pm 1.9$ & $1888.7 \pm 5.9$ & 232.2 & $4062.7 \pm 17.4$ \\
$\mathrm{YbVO}_{4}$ & 1778.6 & $(88.4 \pm 2.0)$ & 1814.6 & 152.1 & $4212.6 \pm 2.5$ \\
$\mathrm{LuVO}_{4}$ & 1806.5 & $85.6 \pm 2.0$ & 1878.2 & 427.6 & $3905.5 \pm 38.7$ \\
\hline
\end{tabular}

Data taken from: ${ }^{(a)}$ Ref. 14; ${ }^{(b)}$ Ref. 13; ${ }^{\left({ }^{c}\right)}$ Ref. 17; ${ }^{(d)}$ Ref. 20.

$$
U_{\mathrm{POT}}=A I\left(\frac{2 I}{v_{\mathrm{m}}}\right)^{\frac{1}{3}}
$$

where $A=121.39 \mathrm{~kJ} \mathrm{~mol}^{-1} \mathrm{~nm}$ is an electrostatic factor, $I=0.5 \sum n_{\mathrm{i}} z_{\mathrm{i}}^{2}$ is the ionic strength with $n_{\mathrm{i}}$ being the number of ions with charge $z_{\mathrm{i}}$ per formula, $I=25$ for $\mathrm{LnVO}_{4}$, and $v_{\mathrm{m}}$ is the molecular volume in $\mathrm{nm}^{3}$. The necessary values of $v_{\mathrm{m}}$ are given in Table 4 .
According to Eq. (3), both quantities $\Delta_{\mathrm{L}} H^{\circ}$ and $\Delta_{\mathrm{L}} U$ are related by factors proportional to $R T=$ $2.48 \mathrm{~kJ} \mathrm{~mol}^{-1}$ at $T=298.15 \mathrm{~K}$, i.e. by $7.44 \mathrm{~kJ} \mathrm{~mol}^{-1}$. The latter presents only $0.03 \%$ of the value of $\Delta_{\mathrm{L}} H^{\circ}$. The values in the last column of Table 4 determined by the empirical Eq. (4) are about 1-3\% lower than those yielded by the Born-Haber cycle. It has been indicated that the empirical formula used to obtain the last column in Table 4 results in estimates with certainty $\pm 7 \%$ compared to the known values. ${ }^{19}$

Table 4. Molecular $\left(v_{\mathrm{m}}\right)$ and molar $\left(V_{\mathrm{m}}\right)$ volumes and lattice energies of lanthanide orthovanadates

\begin{tabular}{cccccc}
\hline $\mathrm{LnVO}_{4}$ & $v_{\mathrm{m}} / 10^{-30} \mathrm{~m}^{3}$ & $V_{\mathrm{m}} / 10^{-6} \mathrm{~m}^{3} \mathrm{~mol}^{-1}$ & $\begin{array}{c}\Delta_{\mathrm{L}} H^{\circ} / \mathrm{kJ} \mathrm{mol}^{-1} \\
\text { this work }\end{array}$ & $\begin{array}{c}\Delta_{\mathrm{L}} H^{\circ} / \mathrm{kJ} \mathrm{mol}^{-1} \\
\text { this work }\end{array}$ & $\Delta_{\mathrm{L}} U^{(\mathrm{c})} / \mathrm{kJ} \mathrm{mol}-1$ \\
\hline $\mathrm{CeVO}_{4}$ & 87.98 & 52.98 & $25944 \pm 18$ & $25889 \pm 13$ & 25137 \\
$\mathrm{PrVO}_{4}$ & 86.67 & 52.19 & $25909 \pm 14$ & $25927 \pm 13$ & 25263 \\
$\mathrm{NdVO}_{4}$ & 87.55 & 52.72 & $25954 \pm 44$ & $25963 \pm 42$ & 25178 \\
$\mathrm{SmVO}_{4}$ & 83.64 & 50.37 & $26000 \pm 44$ & $26013 \pm 42$ & 25565 \\
$\mathrm{EuVO}_{4}$ & 83.28 & 50.15 & $26040 \pm 23$ & $26063 \pm 43$ & 25602 \\
$\mathrm{GdVO}_{4}$ & 81.98 & 49.37 & $26063 \pm 29$ & $26080 \pm 23$ & 25736 \\
$\mathrm{TbVO}_{4}$ & 81.47 & 49.06 & $26114 \pm 28$ & $26127 \pm 23$ & 25790 \\
$\mathrm{DyVO}_{4}$ & 80.29 & 48.35 & $26092 \pm 46$ & $26129 \pm 41$ & 25915 \\
$\mathrm{HoVO}_{4}$ & 79.77 & 48.04 & $26171 \pm 26$ & $26170 \pm 23$ & 25972 \\
$\mathrm{ErVO}_{4}$ & 78.96 & 47.55 & $26171 \pm 25$ & $26201 \pm 23$ & 26060 \\
$\mathrm{TmVO}_{4}$ & 78.17 & 47.08 & $26210 \pm 25$ & $26218 \pm 21$ & 26148 \\
$\mathrm{YbVO}_{4}$ & 77.47 & 46.65 & $26221 \pm 8$ & $26247 \pm 6$ & 26226 \\
$\mathrm{LuVO}_{4}$ & 76.93 & 46.33 & $26237 \pm 44$ & $26244 \pm 42$ & 26287 \\
\hline
\end{tabular}

(a) Obtained with $\Delta_{\mathrm{f}, \mathrm{ox}} H^{\circ}$.

(b) Obtained with $\Delta_{\mathrm{f}, \mathrm{el}} H^{\circ}$.

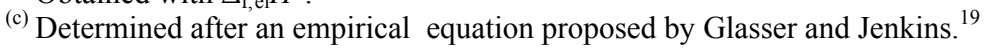




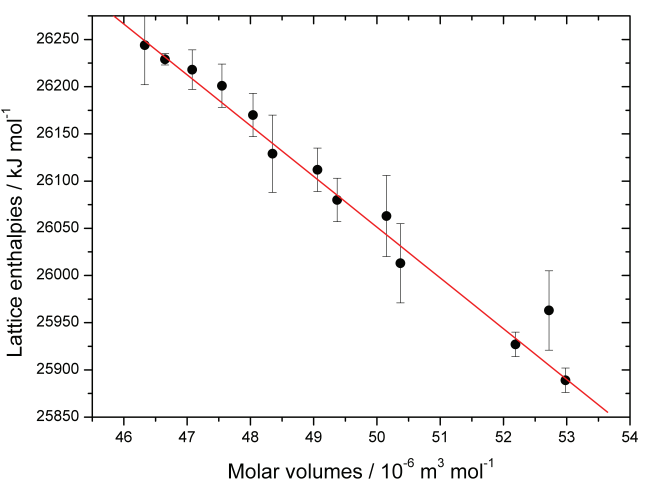

Figure 1. Variation of the lattice enthalpies $v s$. molar volumes of $\mathrm{LnVO}_{4}$.

A direct comparison of the lattice enthalpies obtained by the Born-Haber cycle reported here with those found by the dielectric chemical bond method ${ }^{15}$ is not possible since the latter contains only bond length energies. However, averaging the values for $\mathrm{Ln}-\mathrm{O}$ and $\mathrm{Ln}-\mathrm{O}^{I}$ bonds, and after summation with the values for $\mathrm{V}-\mathrm{O}$ bonds, rough estimates of the lattice energies could be obtained, namely from $25763 \mathrm{~kJ} \mathrm{~mol}^{-1}$ $\left(\mathrm{CeVO}_{4}\right)$ to $25969 \mathrm{~kJ} \mathrm{~mol}^{-1}\left(\mathrm{LuVO}_{4}\right)$, i.e. they are close to those in this work of Table 4.

It should be noted that the $\Delta_{\mathrm{L}} H^{\circ}$ values reported here are derived from experimental values of CSE included in Eq. (1) and that they do not depend on possible mechanisms of summation of pair interactions, structural features, etc.

The plot of lattice enthalpies $v s$. molar volumes of $\mathrm{LnVO}_{4}$ (with CSE of formation of $\mathrm{LnVO}_{4}$ from elements) is presented in Figure 1. The straight line has a regression coefficient $R^{2}=0.9848$ and a negative slope $\left(\partial \Delta_{\mathrm{L}} H^{\circ} / \partial V_{\mathrm{m}}\right)=-51.71 \times 10^{6} \mathrm{~kJ} \mathrm{~m}^{-3}$, or $\left(\partial \Delta_{\mathrm{L}} H^{\circ} / \partial \mathrm{V}_{\mathrm{m}}\right)=$ $-51.71 \times 10^{9} \mathrm{~Pa}$. The negative sign of the slope accounts for the trend of changes of lattice enthalpies $v s$. molar volumes within the series of lanthanide orthovanadates. Thus, an upper limit for the shear modulus of $\mathrm{LnVO}_{4}$, $G=51.7 \mathrm{GPa}$, has resulted in this case. The molar volumes $V_{\mathrm{m}}$ of $\mathrm{LnVO}_{4}$ have been determined here by means of the corresponding densities from X-ray diffraction studies. ${ }^{21}$ Taking the molar volume of $\mathrm{PmVO}_{4}$ as a mean value between those of $\mathrm{NdVO}_{4}$ and $\mathrm{SmVO}_{4}$, the missing lattice enthalpy of $\mathrm{PmVO}_{4}$ has been estimated, $\Delta_{\mathrm{L}} H^{\circ}=25979 \mathrm{~kJ} \mathrm{~mol}^{-1}$.

It should be noted that the variation of the lattice enthalpies vs. molar volumes of $\mathrm{LnVO}_{4}$ (with CSE of formation of $\mathrm{LnVO}_{4}$ from oxides) results in similar straight line with slope $-48.02 \times 10^{9} \mathrm{~Pa}$ and a regression coefficient $R^{2}=0.9556$.

It is important to note that the novelty of the present study is equally based (except the lattice energies) on the physical meaning and dimension obtained from the slope $\left(\partial \Delta_{\mathrm{L}} H^{\circ} / \partial V_{\mathrm{m}}\right)$ since only this slope preserves a correct shear modulus dimension: $\left[\mathrm{J} \mathrm{m}^{-3}\right]=$ [Pa]. Any other linear plot, e.g. $\Delta_{\mathrm{L}} \mathrm{H}^{\Theta}-v_{\mathrm{m}}{ }^{1 / 3}$ would result in dimension $\left[\mathrm{N} \mathrm{mol}^{-1}\right]$ and unclear physical meaning. Therefore, a possible improvement of the regression coefficient $R^{2}$ cannot be a priority task.

The slope $\left(\partial \Delta_{\mathrm{L}} H^{\circ} / \partial V_{\mathrm{m}}\right)$ and shear moduli have the same dimension $[\mathrm{Pa}]$; it is reasonably that a displacement of ions can be related to shear modulus. The meaning of the slope is of an upper limit of energy that, after being absorbed, would result in lattice deformation. Recent measurements of the shear modulus of $\mathrm{GdVO}_{4}$ by ultrasonic technique have revealed a value of $G=40.5 \mathrm{GPa}^{6}{ }^{6}$ The same authors have obtained theoretical values of $G=49.8 \mathrm{GPa}$ or $53.0 \mathrm{GPa}$ by two theoretical approximations. These results confirm an upper limit of the shear moduli $G \approx 50 \mathrm{GPa}$, an average value of both slopes, found in this work. The thermodynamic relations between the internal energy and the moduli of a solid are known at least for crystals of simple structure and small molar volumes. ${ }^{16}$

\section{CONCLUSION}

The lattice enthalpies $\Delta_{\mathrm{L}} H^{\circ}$ of $\mathrm{LnVO}_{4}$ increase slightly with increasing the atomic number in the lanthanide series and remain close to those determined by an empirically derived equation. The dependence between $\Delta_{\mathrm{L}} H^{\circ}$ and molar volumes $V_{\mathrm{m}}$ is linear with a negative slope. The latter corresponds to lattice enthalpy per molar volume and can be considered as an upper limit of the shear moduli for the series of $\mathrm{LnVO}_{4}$.

Acknowledgements. The author would like to thank Assoc. Prof. D. Kovacheva for providing the values of the XRDdensities of $\mathrm{LnVO}_{4}$, Prof. L. Glasser and Prof. B. M. Angelov for valuable suggestions.

\section{REFERENCES}

1. S. Mahapatra, R. Vinu, T. N. Guru Row, and G. Madras, Appl. Catal. A: Gen. 351 (2008) 45-53.

2. J. Xu, C. Hu, G. Liu, H. Liu, G. Du, and Y. Zhang, J. Alloys Compd. 509 (2011) 7968-7972.

3. W. Ryba-Romanowski, Cryst. Res. Technol. 38 (2003) 225-236.

4. S. Miazawa, Opto-Electron. Rev. 11 (2003) 77-84.

5. M. Dragomir, I. Arčon, S. Gardonio, and M. Valant, Acta Mater. 61 (2013) 1126-1135.

6. Z. Huang, L. Zhang, J. Feng, X. Cui, and W. Pan, J. Alloys Compd. $\mathbf{5 3 8}$ (2012) 56-60.

7. A. H. Krumpel, P. Boutinaud, E. van der Kolk, and P. Dorenbos, J. Lum. 130 (2010) 1357-1365.

8. M. R. Dolgos, A. M. Paraskos, M. W. Stoltzfus, S. C. Yarnell, and P. M. Woodward, J. Solid State Chem. 182 (2009) 1964 1971.

9. M. Moussa, M. Djermouni, S. Kacimi, M. Azzouz, A. Dahani, and A. Zaoui, Comput. Mater. Sci. 68 (2013) 361-366.

10. O. Ermakova, W. Paszkowicz, J. Lopez-Solano, A. Muňoz, and H. Dabkowska, Acta Phys. Polon. A 121 (2012) 920-923. 
11. T. Aldred, Acta Crystallogr. B 40 (1984) 569-574.

12. K. Oka, H. Unoki, H. Shibata, and H. Eisaki, J. Crystal Growth 286 (2006) 288-293.

13. M. Dorogova, A. Navrotsky, and L. A. Boatner, J. Solid State Chem. 180 (2007) 847-851.

14. H. Yokokawa, N. Sakai, T. Kawada, and M. Dokiya, J. Am. Ceram. Soc. 73 (1990) 649-658.

15. S. Zhang, S. Zhou, H. Li, and L. Li, Inorg. Chem. 47 (2008) 7863-7867.

16. P. Atkins and J. De Paula, Physical Chemistry, Oxford University Press, Oxford, 2006, pp. 719-722.
17. D. Lide, CRC Handbook of Chemistry and Physics, CRC Press, Boca Raton, 2004, p. 85

18. C. I. Smithels, Metals Reference Book, Butterworths, London, 1976, p. 138.

19. L. Glasser and H. D. B. Jenkins, J. Am. Chem. Soc. 122 (2000) 632-638.

20. W. C. Martin, L. Hagan, and J. Sugar, J. Phys. Chem. Ref. Data 3 (1974) 771-780

21. ICDD-PDF2-file No. 01-082-(1972-1977), 01-074-(8274, 8275), 01-075-(9378- 9380), 01-086-0995. 